\title{
Difficulty of getting accurate and precise estimates of population size: the case of the Siberian flying squirrel in Finland
}

\author{
Risto Sulkava1 ${ }^{1}$ Antero Mäkelä², Janne S. Kotiaho³ \& Mikko Mönkkönen³ \\ 1) Department of biology, University of Joensuu, Fl-80101 Joensuu, Finland; and Aaponkaari 3, \\ Fl-42800 Haapamäki, Finland (e-mail: risto.sulkava@pp.inet.fi) \\ 2) Linnantie 10, Fl-63350 Sulkavankylä, Finland \\ 3) Department of Biological and Environmental Sciences, P.O. Box 35, Fl-40014 University of \\ Jyväskylä, Finland
}

Received 21 Aug. 2007, revised version received 28 Mar. 2008, accepted 23 Apr. 2008

Sulkava, R., Mäkelä, A., Kotiaho, J. S. \& Mönkkönen, M. 2008: Difficulty of getting accurate and precise estimates of population size: the case of the Siberian flying squirrel in Finland. - Ann. Zool. Fennici 45: 521-526.

Accurate estimates of population size and distribution are a prerequisite for effective management of populations, but for most species a reliable estimation of the absolute population size is very difficult. In 1998, the Finnish Ministry of Environment set up a working group to plan a national-level survey for estimation and monitoring of the population size of Siberian flying squirrel (Pteromys volans). In 2006, the population size was reported to be 143000 females. However, evaluation of the magnitude of possible biases was not attempted. Our aim was to test the population size estimate by conducting a resampling study with the methods of the national survey on an eartagged population of flying squirrels. We found that the methods used in the national survey provide greatly upward biased estimates. Moreover, the magnitude of the bias in the method seems to be sensitive to the true population sizes rendering the method unsuitable for population trend monitoring purposes. Therefore, we caution against using the national survey method in monitoring or in making conclusions about the population size of the Siberian flying squirrel.

\section{Introduction}

Reliable knowledge of population size and distribution is a prerequisite for effective management of populations of endangered species. However, for most species a reliable estimation of the absolute population size is very difficult, if not impossible, to obtain. Thus, the management of populations of endangered species is often based on some alternative information. One type of knowledge that can readily be obtained from well-designed monitoring schemes are population trends, i.e., changes in estimated population size relative to previous censuses. In this case, a bias in the estimate of the true population size is not critical, provided that the current and previous censuses provide similarly biased estimates of the population. When such a monitoring scheme is not in place, the conservation need of a species must be based on an accurate and 
precise estimate of the population size. In such a case, avoiding biases in the estimation of the population size is of paramount importance.

In 1998, the Finnish Ministry of Environment established a working group to assess the conservation needs of the Siberian flying squirrel (Pteromys volans) populations in Finland, and to plan a national survey for estimation and monitoring of the population size. The flying squirrel is included in the list of EU Nature directive species (appendix IVa) and according to the Finnish Nature Protection Act, the breeding or resting sites may not be destroyed or deteriorated (http://ec.europa.eu/environment/nature/ legislation/habitatsdirective/index_en.htm). The species is classified as endangered (vulnerable) in Finland (Rassi et al. 2001) because of the assumed rapid population decline. Even though the populations of the flying squirrel are considered to have diminished in Finland consistently since the 1940s (e.g. Hokkanen et al. 1982, Hanski et al. 2001, Hanski 2006), reliable estimates of the population size have not been available (Hokkanen 1996, Hokkanen et al. 2001, Reunanen \& Mönkkönen 2001). Recently the working group attempted to rectify the situation by publishing the results of the national survey, providing an estimate of the female population size (Hanski 2006).

Here our aim is to empirically test the accuracy of the population size estimation method, which was employed by the national survey method (Hanski 2006). This was achieved by conducting a resampling study, using the same method as in the national survey (Hanski 2006), on an ear-tagged population of Siberian flying squirrels, which has been closely monitored for more than 20 years.

\section{Methods}

\section{The reference study: the National Survey Method (NSM)}

The national survey method for estimating the population size of the flying squirrel (Hanski 2006) was based on observing the presence or absence of easily-detected scent marks and faecal pellets of the flying squirrels in a systematic sample grid. The sample grid was constructed so that the entire southern Finland was divided into $10 \mathrm{~km} \times 10 \mathrm{~km}\left(100 \mathrm{~km}^{2}\right)$ squares, every second of which was systematically included in the survey. Within each of the $100-\mathrm{km}^{2}$ square in the study, ten 9-ha squares were randomly positioned so that at least two thirds of each square were on suitable forest land, and all squares were at least $1 \mathrm{~km}$ from each other. The 9-ha squares were subsequently visited by trained surveyors to assign them as occupied $v s$. unoccupied, based on the scent marks and faecal pellets. It is critical to note that the sex of the individual that left the marks and faecal pellets cannot be determined. A total of $10022(10.3 \%)$ of the 9-ha squares were determined to be occupied, and this result was extrapolated over the suitable forest land area in southern Finland (Hanski 2006).

In the NSM, 9-ha sampling unit was assigned to match the average female home range of 8.3 ha in southern Finland (Hanski et al. 2000b). An occupied sampling unit was assumed to be indicative of one female living in the unit based on the fact that female flying squirrels are territorial (e.g. Hanski et al. 2000a, 2000b, A. Mäkelä, unpubl. data). Information on the biology of the species can be found elsewhere (Mäkelä 1981, Eronen 1990, Hanski 1998, Sulkava \& Sulkava 1998, Hanski et al. 2000a, Reunanen 2001, Selonen et al. 2001, Wistbacka et al. 2001, Reunanen et al. 2002). The 1-km distance rule was adopted to ensure that the occupancy status of the squares was independent of each other. This sampling scheme was assumed to provide a reliable estimate of the female population size (for details of the survey method see Hanski 2006). However, no attempt to evaluate the magnitude of possible biases in the method was made, and consequently, we do not know how accurate the resulting estimate of the total population size of 143000 females in Finland actually is, and whether the estimation method itself introduces some bias into the estimate.

\section{The control population: ear-tagged population of known size}

Distribution and abundance of a flying squirrel population in Alavus, western Finland, were 
monitored from 1976 to 2006 (e.g. Mäkelä 1981, 1996, 1999, 2001). This is a population breeding in nest boxes, which makes it possible to ear-tag and monitor practically all individuals present in the population. Individuals that were ear-tagged earlier were monitored yearly at the same time with ear-tagging of the newborn individuals. Although there are also dreys and some natural cavities in the study area, all flying squirrels used nest boxes at least part of the time, and so live capture was possible. We have been able to catch a squirrel in all forest areas in which faecal pellets were found more than occasionally. In cases where we found pellets from an area without a nest box, we placed one there, and in each case we sooner or later caught a squirrel from the box.

The most intensive monitoring involved an area of $114 \mathrm{~km}^{2}$. During the 20 years, the annual intensity of the monitoring varied between two and six trapping rounds of all boxes, but for two of the most intensive study years, 1981 and 1998 , a reliable estimate of the true population size and its distribution is available. In addition to the identity and location of each individual within the study area in these two years, our data comprises detailed information on the location of faecal pellets found in the same two years. The scent marks and faecal pellets were sought in all forested areas, and all trees with signs of flying squirrels were marked on the maps. Regardless of the intensity of the study during the two years, there remains a small possibility that some females remained undetected in the survey. For this reason, we estimated a minimum and maximum number of females present in the study area. The minimum number of females is the actual number of ear-tagged females observed inside the study area in the particular year. The maximum number includes also assumed females i.e. home ranges that were observed to be occupied by a female flying squirrel in previous years, and included scent marks in the study year, but in which the female was not directly observed in the study year. It is possible that in these home ranges there were no female present, a female was present but occupied an unknown nest or that there were only males present. However, as the fieldwork was very intensive during the two years, we believe that the true total number of females in the study area is closer to the minimum rather than the maximum estimate.

\section{Testing of the accuracy of the National Survey Method (NSM)}

We thus had the possibility to compare two independent estimates of the population size of female flying squirrels in our intensive study area for two years, 17 years apart (1981 and 1998). Employing the two estimates of the true population size and detailed faecal pellet maps, we could empirically test the accuracy of the NSM. To do this, we adopted exactly the same survey method as the national survey. We placed a 10 $\mathrm{km} \times 10 \mathrm{~km}$ square in our study area of $114 \mathrm{~km}^{2}$. Within this $100 \mathrm{~km}^{2}$ square we randomly placed ten 9-ha squares following the placement rules given in the national survey method (Hanski et al. 2001, Hanski 2006) and determined the presence or absence of faecal pellets in each square. We repeated the random placement of the ten 9-ha squares 78 times, to allow estimation of confidence intervals for the estimate of the population size.

We then calculated the mean value of the number of occupied 9-ha squares in the 78 sets of ten squares. We used bootstrapping to estimate the $95 \%$ confidence interval for the mean. The 78 sets of ten squares were resampled with replacement for 1000 times. For each resample, we calculated the mean number of occupied squares, and discarded the 25 smallest and 25 largest mean values. The minimum and maximum values in these reduced data provide lower and upper limits of the $95 \%$ confidence interval. This procedure was done separately for the years 1981 and 1998.

An estimate of the number of females in the study area was calculated following the methods used in the NSM (Hanski 2006). We multiplied the mean frequency of occupied squares by the area of suitable forest land (7733 ha) in the study area and divided this by the surveyed area ( 90 ha). In addition to verifying whether the population size estimate of the NSM is unbiased, we used two temporally independent (separated by 17 years) censuses of the same study area. This made it possible to assess if the NSM could be used for 


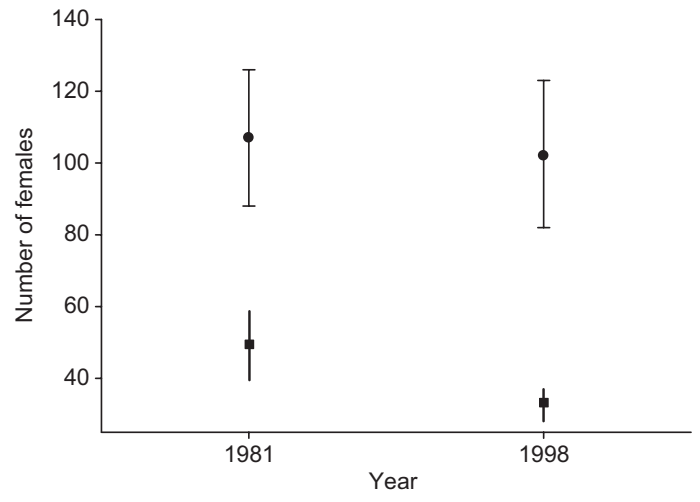

Fig. 1. Numbers of females in our study area in 1981 and 1998 based on monitoring the ear-tagged population [means (square) with ranges (min-max)] and national flying squirrel survey method (means (dot) with $95 \%$ confidence intervals).

detecting changes in population abundance, i.e. whether the method is suitable for monitoring the Siberian flying squirrel population trends.

\section{Results and discussion}

In our study area of $100 \mathrm{~km}^{2}$, the true population size of females was 40-59 females (minimum and maximum) in 1981 and 28-37 females in 1998. However, for the same area, the national flying squirrel survey method yielded estimates of population size of 107 (95\% CI $=88-126)$ and $102(95 \% \mathrm{CI}=82-123)$ females in 1981 and 1998, respectively (Fig. 1). In other words, the NSM overestimated the population size on average 2 (in 1981) to 3 (in 1998) times in comparison with the true population size of females.

In the NSM, Hanski (2006) observed that across southern Finland, on average, $10.3 \%$ of the 9-ha squares were occupied by flying squirrels. The respective number for the region (EteläPohjanmaa) where our study area is located was $14.7 \%$ (Hanski 2006). In our study we observed that on average, about $12.4 \%$ (1981) and $11.9 \%$ (1998) of the squares were occupied. Therefore, our study area is a representative $100 \mathrm{~km}^{2}$ square in this region, further confirming that our results can be used to assess the accuracy of the national survey.

Our results indicate that the national flying squirrel survey method severely overestimates the true female population size. The true density of females per $\mathrm{km}^{2}$ of the suitable forest land of our study area was 0.65 in 1981 and 0.43 in 1998, while the NSM produced densities of $1.38(95 \% \mathrm{CI}=1.14-1.62)$ in 1981 and 1.32 (95\% CI $=1.05-1.60)$ females per $\mathrm{km}^{2}$ in 1998 . Hanski (2006) estimated that the female population size in the region of our study is about 14 900 females in total and about 1.2 females per $\mathrm{km}^{2}$ of suitable forest land. Our results suggest that these are overestimates and in reality, there are only 5000 to 7000 flying squirrel females in the region (based on the more recent 1998 data). More importantly, our results suggest that the total Finnish population is perhaps less than half of the reported 143000 females (Hanski 2006).

We can think of one clear reason for the overestimate of the true population size that is the large difference in the home-range size of male and female Siberian flying squirrels. Females inhabit home ranges averaging 8.3 ha, whereas males use home ranges averaging 60 ha in size and can move distances longer than $1 \mathrm{~km}$ during a single night (Hanski 1998, Hanski et al. 2000a and 2000b). Moreover, females are territorial and thus maintain separate home ranges without any overlap, but male home ranges overlap with each other and often also with several females (Hanski 1998, Hanski et al. 2000a, A. Mäkelä, unpubl. data). The NSM interprets even a single faecal pellet as an indicator of female occupation, i.e. as an indicator of a female living in the area. However, it is not possible to tell in the field whether the pellets originate from a male or a female. The upward bias in the NSM is likely because male flying squirrels leave pellets also en route as they move between areas (Sulkava \& Sulkava 1998, R. Sulkava \& A. Mäkelä unpubl. data).

The true population size of our ear-tagged population declined by about $30 \%$ between 1981 and 1998. The NSM overestimation appeared to be more severe in 1998, when the population size was smaller, suggesting that the magnitude of the bias in the method may be sensitive to the true population size. Such sensitivity of the bias is fatal when the method is considered to be used in monitoring population trends: when populations decline, the survey method results in increasingly upward biased population size estimate. 
This will lead to an erroneous conclusion that no change in population size has occurred. The increasing bias with decreasing population size may stem from the same mechanism as the population size overestimation: at lower population density, males are likely to move more widely and leave tracks of their presence. This is in fact an example of a classic problem of survey methods that are based on presence-absence data; such methods may not be sensitive to changes in population abundance before populations reach very low levels (Tosh et al. 2004, Nielsen et al. 2005, Joseph et al. 2006).

We conclude that the method used in the national flying squirrel survey provides imprecise several-fold upward biased estimates of the female population size. Moreover, there is indicative evidence that the magnitude of the bias in the method may be sensitive to the true population size, rendering the method in its current state unsuitable for population trend monitoring purposes. Therefore, without more studies we caution against using the NSM in monitoring and especially in making conclusions about the population size of the Siberian flying squirrel in Finland.

\section{Acknowledgements}

We thank Jouni Kalmari and Pertti Sulkava for their help in the field. This study was supported by the Centre of Excellence in Evolutionary Research.

\section{References}

Eronen, P. 1990: Liito-oravan (Pteromys volans) elinympäristöt: tyyppiryhmittely, suisituimmuus ja valintaan vaikuttavat tekijät. - M.Sc. thesis, Department of Ecology, Univeristy of Jyväskylä.

Hanski, I. K. 1998: Home ranges and habitat use in the declining flying squirrel Pteromys volans in managed forests. - Wildlife Biology 4: 33-46.

Hanski, I. K. 2006: Liito-oravan Pteromys volans Suomen kannan koon arviointi. - Report, Ympäristöministeriö, Helsinki.

Hanski, I. K., Mönkkönen, M., Reunanen, P. \& Stevens, P. 2000a: Ecology of the Eurasian flying squirrel (Pteromys volans) in Finland. - In: Goldingay, R. \& Scheibe, J. (eds.), Biology of gliding mammals: 67-86. Filander Verlag, Fürth.

Hanski, I. K., Stevens, P., Ihalempiä, P. \& Selonen, V. 2000b:
Home-range size, movements, and nest-site use in the Siberian flying squirrel, Pteromys volans. - Journal of Mammalogy 81: 798-809.

Hanski, I. K., Henttonen, H., Liukko, U.-M., Meriluoto, M. \& Mäkelä, A. 2001: Liito-oravan (Pteromys volans) biologia ja suojelu Suomessa [Biology and conservation of the Siberian flying squirrel (Pteromys volans) in Finland]. - Suomen Ympäristö, Luonto ja Luonnonvarat 459. [In Finnish with English abstract].

Hokkanen, H. 1996: Liito-oravan kannankehitys ja sen seuranta. - Maailman Luonnon Säätiön WWF Suomen rahaston raportteja 8: 6-11.

Hokkanen, H., Törmälä, T. \& Vuorinen, H. 1982: Decline of the flying squirrel Pteromys volans L. populations in Finland. - Biological Conservation 23: 273-284.

Hokkanen, H., Eronen, P. \& Paakkonen, J. 2001: Liito-oravaatlas: liito-oravien kannankehitys ja yksilömäärä Suomessa. - Suomen Ympäristö 459: 85-89

Joseph, L. N., Field, S. A., Wilcox, C. \& Possingham, H. P. 2006: Presence-absence versus abundance data for monitoring threatened species. - Conservation Biology 20: 1679-1687.

Mäkelä, A. 1981: Liito-oravan Pteromys volans L. ravintobiologiasta. - M.Sc. thesis, Department of Biology, Univeristy of Oulu.

Mäkelä, A. 1996: Liito-oravan (Pteromys volans L.) lisääntymisbiologiasta. - Maailman Luonnon Säätiön WWF Suomen rahaston raportteja 8: 63-66.

Mäkelä, A. 1999: Liito-oravan elinalueet ja elinympäristön määrä Alavudella 1981 ja 1998. -Luonnon Tutkija 103: $56-57$.

Mäkelä, A. 2001: Liito-oravan (Pteromys volans L.) esiintyminen ja lajille sopivan elinympäristön määrä Alavuden Sulkavankylän tutkimusalueella vuosien 1981 ja 1998 inventointien perusteella. - Suomen Ympäristö 459: 76-80

Nielsen, S. E., Johnson, C. J., Heard, D. C. \& Boyce, M. S. 2005: Can models of presence-absence be used to scale abundances? Two case studies considering extremes in life history. - Ecography 28: 197-208.

Rassi, P., Alanen, A., Kanerva, T. \& Mannerkoski, I. (eds.) 2001: Suomen lajien uhanalaisuus 2000 [Monitoring of threatened animals in Finland]. - Committee report, Ympäristöministeriö and Suomen ympäristökeskus, Helsinki. [In Finnish with English summary].

Reunanen, P. 2001: Landscape responses of the Siberian flying squirrel (Pteromys volans) in northern Finland. - Ph.D. thesis, Department of Biology, University of Oulu.

Reunanen, P., Mönkkönen, M. \& Nikula, A. 2002: Habitat requirements of the Siberian flying squirrel in northern Finland: comparing field survey and remote sensing data. - Annales Zoologici Fennici 39: 7-20.

Reunanen, P. \& Mönkkönen, M. 2001: Kuinka monta liitooravaa Suomessa todella on? Kriittisiä huomautuksia liito-oravan kannanarvioon Suomessa. - Suomen Ymрӓristö 459: 101-104.

Selonen, V., Hanski, I. K. \& Stevens, P. C. 2001: Space use of the Siberisan flying squirrel Pteromys volans in fragmented forest landscapes. - Ecography 24: 588-600.

Sulkava, R. \& Sulkava, P. 1998: Metsänkäsittelyn vaikutus 
liito-oraviin. - Luonnon Tutkija 102: 56-59.

Tosh, C. A., Reyers, B. \& van Jaarsveld, A. S. 2004: Estimating the abundances of large herbivores in the Kruger National Park using presence-absence data. - Animal
Conservation 7: 55-61.

Wistbacka, R., Backman, M. Jakomsson, R. \& Helle, S. 2001: Flygekorrens förekomst och biotopval i Jakobstad 1993 och 1999. - Suomen Ympäristö 459: 91-100. 